IRA-International Journal of Management \&

Social Sciences

ISSN 2455-2267; Vol.16, Issue 01 (Jan.-March, 2020)

Pg. no. 23-30.

Institute of Research Advances

http://research-advances.org/index.php/RAJMSS

QUARTERLY

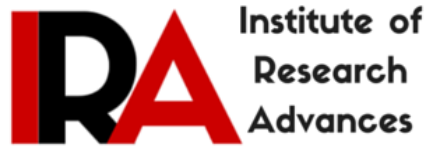

\title{
Influence of Sexual Violence on Perceived Anxiety among Married Couples in Makurdi Metropolis
}

\author{
Joyce Mcivir Terwase ${ }^{1 \#}$, Cyprian Lawrence Achubu² \& Cyril Iligh ${ }^{3}$ \\ ${ }^{1,2}$ Department of Psychology, Benue State University, Makurdi, Nigeria. \\ ${ }^{3}$ Department of Educational Foundations and General Studies, University of Agriculture, Makurdi, \\ Nigeria.
}

\# corresponding author

Type of Work: Peer Reviewed.

DOI: http://dx.doi.org/10.21013/jmss.v16.n1.p2

How to cite this paper:

Terwase, J.M., Achubu, C.L., Iligh, C. (2020). Influence of Sexual Violence on Perceived Anxiety among Married Couples in Makurdi Metropolis. IRA-International Journal of Management \& Social Sciences (ISSN 2455-2267), 16(1), 23-30. doi:http://dx.doi.org/10.21013/jmss.v16.n1.p2

(C) Institute of Research Advances.

(cc) BY-Ne

This work is licensed under a Creative Commons Attribution-Non Commercial 4.0 International License subject to a proper citation to the publication source of the work.

Disclaimer: The scholarly papers as reviewed and published by the Institute of Research Advances (IRA) are the views and opinions of their respective authors and are not the views or opinions of the IRA. The IRA disclaims of any harm or loss caused due to the published content to any party.

Institute of Research Advances is an institutional publisher member of Publishers International Linking Association Inc. (PILA-CrossRef), USA. The institute is an institutional signatory to the Budapest Open Access Initiative, Hungary advocating the open-access of scientific and scholarly knowledge. The Institute is a registered content provider under Open Access Initiative Protocol for Metadata Harvesting (OAI-PMH).

The journal is indexed \& included in WorldCat Discovery Service (USA), CrossRef Metadata Search (USA), WorldCat (USA), OCLC (USA), Open J-Gate (India), EZB (Germany) Scilit (Switzerland), Airiti (China), Bielefeld Academic Search Engine (BASE) of Bielefeld University, Germany, PKP Index of Simon Fraser University, Canada. 


\begin{abstract}
Many issues in marital relationships often lead to anxiety problems amongst couples, particularly, sexual violence which includes harassment, sexual exploitation, and assault, etc., are behaviors that call for the attention of mental health professionals. The growing cases of marital unhappiness have drawn the researcher's attention globally and the existing gaps form the rationale for this study. The cross-sectional survey design was adopted while the stratified random and non-probability sampling techniques were used to sample the population and participants for the study. A total of 251 participants took part in the study, while males were 126(50.2\%), females were 125(49.8\%) with ages ranging from 20years and above. Two instruments were used to collect data; Beck Anxiety Inventory (BAI) developed by Beck et al. (1988) and Sexual Violence and Physical Abuse (SVPA) Scale developed by Lesserman et al. (1995). Three hypotheses were tested using Multiple Regression Analysis. The result of hypothesis one revealed a significant influence of gender, age and occupation on perceived anxiety, hypothesis two showed a significant influence of sexual violence on perceived anxiety, while hypothesis three revealed a significant joint influence of gender, age, occupation and sexual violence on perceived anxiety. In conclusion, the three hypotheses were accepted as significantly influencing perceived anxiety amongst married couples in Makurdi Metropolis. Two key recommendations include marital counseling and administering psychological interventions to curb negative behavior.
\end{abstract}

Keywords: Influence, Sexual violence, Perceived anxiety, Married couple

\title{
Introduction
}

Many issues in marital relationships often lead to anxiety problems among married couples particularly sexual violence which includes harassment, sexual exploitation, and assault, etc., all these are behaviors that call for the attention of mental health professionals. Miller-Keane, (2003) in the medical dictionary defines anxiety as a commonplace experience that everyone passes through at various times, although it is stressed that this is difficult to describe concretely as it has many different potential causes and degrees of intensity. A conceptualization of anxiety from the perspective of Bigdeli, (2010) is that anxiety is an unpleasant emotion experienced as a scare, alarm, fright, trepidation, horror or panic. It is also a subjective feeling of apprehension, tension, and nervousness accompanied by the activation of the sympathetic nervous system Ma, (2017).

From the perspective of Thompson, (2011), anxiety is a multisystem response to a perceived threat or danger. It is a unique human experience involving an ability to use memory and imagination to move backward and forward in time (Farlex, 2012). These anxiety experiences are capable of affecting people's everyday lives. However, Ohman, (1993) describes anxiety as a three-component emotional phenomenon and as a subjective experience consisting of an "ineffable and unpleasant feelings of foreboding", also, as a perception of bodily responses as sweating, palpitations, shortness of breath, and as behaviors associated with escape and avoidance. Owen, (1994), describes anxiety as dread and it is associated with dizziness. Anxiety is accompanied by muscular tension, restlessness, fatigue, and problems in concentration. It is a physiological state characterized by cognitive, somatic, emotional and behavioral components that combine to create sweating, dizziness, headache, racing heartbeats, nausea, fidgeting, drumming on a desk, fear, apprehension, and worry (Seligman, Walker \& Rosenhan, 2002). This anxiety experienced among individuals can be appropriate, but when it becomes too regular, the individuals could suffer an anxiety disorder Ormerl, Jeronimus, Kotov, Riese, Bos \& Hankin, 2013).

Anxiety disorders are a group of mental disorders characterized by feelings of anxiety that can be experienced with long drawn out daily symptoms that reduce the quality of life known as generalized or chronic anxiety disorder and can be experienced in short spurt with sporadic stressful panic attacks known as acute or post-traumatic stress disorder (Teigen, 1994). Anxiety disorders affect how we feel and behave which can manifest real physical symptoms most often; mild anxiety is vague and unsettling while severe anxiety can be extremely debilitating, having a serious impact on one's life. Worthy of note, the experience of anxiety could manifest in different ways which include changes in sleeping patterns, nervous habits and increased motor tension like foot tapping; emotionally it is experienced as feelings of apprehension or dread and cognitively, it is experienced in form of thought(s) about suspected dangers such as fears, example such as fear of dying (Mathurs \& Khan, 2011).

As stated in the opening sentence, anxiety could be occasioned by marital issues-particularly sexual violence. This includes violence that is physical or psychological carried out through sexual means or by targeting sexuality which 
could take different forms such as sexual abuse and sexual assault which could happen to anybody regardless of age, gender, ethnicity or sexual orientation of the victim, this implies a sexual act committed against someone without the person's free consent (CDC, 2005). Furthermore, sexual violence includes other forms of sexual behaviors ranging from aggressive sexual behavior such as sex without consent known as rape, (Clark \& Quadara, 2010). Rape is a physically forced or otherwise coerced penetration of the vulva or anus, using a penis or other body parts or an object, and other forms of sexual violence to include incest and child sexual abuse (Olive, 2012). Other components of sexual violence include forced kissing, forced breast and genital fondling, attempted rape and forced exposure to pornography, (West \& Rose, 2000; Eze, 2013).

Sexual violence is a global trend practiced in many countries of the World though with differences in prevalence. Studies on sexual violence have shown that males and females could be assaulted sexually and that the prevalence is more among women than men (Akinlusi, Rabiu, Olawepo, Adewunmi, Othun and Akinola, 2014). There is an indication that sexual violence against men and boys is a significant problem though, it is one area that has to a large extent been neglected in research. The Australian Bureau of Statistics (2005) found sexual violence in terms of gender occurring to more women than men. So, there is evidence that sexual violence against women seems to be most prevalent all over the world, however reliable data shows that there is a variation from one region or location to another. For example, the record has revealed that $12 \%$ of women in Western Europe had experienced non-partner sexual assault (Lewis \& Reed, 2003). While data on the issue in developing countries including Nigeria is not available (Adeleke, et al. 2012).

Sexual violence incidence is not restricted to any age group, both the young and old are affected one way or the other, although the prevalence of sexual violence seems to be more among youths, and especially the category of students (Hill \& Silva, 2005). Other kinds of the prevalence of sexual violence are by age as revealed by (Finkelhor, Hotaling, Lewis \& Smith, 1990), they project that by age 18, one in four girls will be sexually assaulted, by age 18 , one in six boys will be assaulted. Also, that at some point in the lives of women, 1 in six women has experienced an attempted rape, more than half occurred before the age of 18 , and $22 \%$ before the age of 12 (Tjaden \& Thoennes, 2000). Also, during their lives, 1 in 33 men have experienced an attempted or completed rape as a form of sexual violence; $75 \%$ occurred when the men were 18 , and $48 \%$ before age 12 . Globally, rape is regarded as the most demoralizing type of trauma which has very negative implications on the victims and their families. Rape, however, affects the community in general. Moreover, there is little reported literature on rape victimization of the male gender (Mgolozeli, \& Duma, (2019). However, it has been asserted that sexual violence in the form of rape is the most underreported crime as only $30 \%$ of rape was reported to law enforcement agents especially in Nigeria.

This research is out to explore the influence of sexual violence on perceived anxiety among married couples in Makurdi metropolis, and studies have revealed the perception of anxiety experienced by married couples which arises from psychological and physiological state of arousal characterized by increased mobilization of the body to action, such as accelerated heartbeat, sweating and shivering of the hands, breathlessness, tension, headache, dryness of mouth and so on, which affects voice, temper, and tone (Lerner \& Keltner, 2000). Apart from sexual violence experienced among couples which gives rise to anxiety and is the crux of this study, other factors revealed in research include early marriage, changing jobs, hormonal changes, family history of mental health issues and personality traits, raising children, etc. Factors that constitute problems in this study stem from the fact that, in recent times, issues of marital unhappiness and dissatisfaction abound globally and in Africa many of which result in depression and anxiety disorders. WHO, (1999) reviewed that sexual violence results in marital problems and causes psychological distress, fear, anxiety, depression, emotional anger which occurs either in months, years after an incident. Cowan \& Cowan, 2000) found that many married partners experience symptoms of anxiety and fear as a result of greater intimate sexual violence, a decrease in marital satisfaction and a decrease in companionship activities. In Nigeria, marital and relationship problems have given rise to risks related to developmental and life cycle vulnerabilities among married couples.

According to Research by Nigeria Demographic and Health Survey (NDHS, 2008), several dimensions of marital violence include physical, sexual and emotional violence. Odimegwu, \& Okemgbo, (2008) found that sexual violence in marital relationships remains the most vulnerable and poses serious problems to lives and the health and wellbeing of individual families. In Benue State, marital problems inform of sexual violence have been identified as issues contributing to the married couple's domestic violence. However, sexual violence among married couples like other forms of violence against men and women has received little attention due to cultural, legal and misinterpreted religious endorsement (Shija, 2004). Based on the little available information from previous studies, sexual violence, 
especially against women, remains one of the most serious problems constituting a serious health risk; it could also result in anxiety that couples face physically, emotionally, and psychologically (Ogbuji, 2004; Abakhale, 2010). The growing cases of marital unhappiness and the need for building social protections to reduce risks related to the influence of sexual violence and to address couples' vulnerabilities to the risks of perceived anxiety have drawn the researcher's attention globally and the existing gaps form the rationale for this study.

Meanwhile, this study aimed at assessing the influence of sexual violence on perceived anxiety among married couples in Makurdi metropolis and specifically assess if gender, age, and occupation will significantly influence perceived anxiety among couples; to examine the influence of sexual violence on perceived anxiety among married couples and to examine the joint influence of gender, age, occupation and sexual violence on perceived anxiety among married couples.

The research seeks to answer the following questions:

i. Will gender, age, and occupation significantly influence perceived anxiety among married couples?

ii. Will there be a significant influence of sexual violence on perceived anxiety among married couples?

iii. Will there be a significant joint influence of gender, age, occupation and sexual violence on perceived anxiety among married couples?

Two theories were reviewed in this study; the biological theory of anxiety developed by Tallman et al. (1980) and the synthesized biosocial theory of sexual violence developed by Ellis (1991).

The biological theory explains anxiety and holds that problems with perceived anxiety emanate from one or more past traumatic experiences. The theory postulates that anxiety occurs on three basic conditions of overstimulation which refers to when a person is flooded with information; Cognitive Congruity which is when a person has difficulty reconciling with some events; and Response Unavailability which refers to when a person does not know how to handle a difficult situation. According to the biological theory, the system responsible for the activation of anxiety is GABA which is inhibition neurotransmitters. The theory explains that those who experience more anxiety than others fail to produce or release chemicals called benzodiazepines which are necessary for amounts of GABA needed to regulate neural transmission.

The synthesized theory of sexual violence also known as Biosocial theory holds that sex hormones affect the brain and that sexual violence rest on four main prepositions of sex drive and a drive to possess and control, actually learned techniques, evolution, and variance in tendencies based on the brain functioning. The biosocial theory asserts that sexual act includes rape and that for human beings, sex and possession drives are closely linked and both comprise the motivation behind all sexual behaviors. The theory holds that sexual violence behavior is not exhibited exclusively by males but also by females. This is because females who have a difficult time securing a mate may use coercive means to copulate with highly desirable males.

\section{Hypotheses}

Based on the research questions above, the following research hypotheses were formulated to answer the questions posed by the study.

1. There will be a significant influence of gender, age, and occupation on perceived anxiety among married couples in Makurdi metropolis.

2. There will be a significant influence of sexual violence on perceived anxiety among married couples in Makurdi metropolis.

3. There will be a significant joint influence of gender, age, occupation and sexual violence on Perceived anxiety among married couples in Makurdi metropolis.

\section{Methods}

\section{Research Design}

The research design adopted for this study is the cross-sectional survey design. 


\section{Population}

The population comprised all married people in Makurdi metropolis, however for this study, five areas were randomly sampled through randomization and eventually, five areas were got which were; North Bank, Wurukum, High-level, Wadata, and Modern Market and were sampled for the study. A total of 251 participants took part in the study, while males were $126(50.2 \%)$, females were 125 (49.8\%) with ages ranging from 20 years and above.

\section{Sampling Technique}

The stratified random and non-probability sampling techniques were used to sample the population and participants respectively for the study, and this was also used in choosing participants based on their availability and interest. The kind of non-probability sampling technique used was the purposive sampling technique which was adopted due to the uniqueness of the participants.

\section{Setting}

The setting for this study is Makurdi metropolis and the study covers five selected areas in the said location which include North Bank, Wurukum, High-level, Wadata, and Modern Market. The participants for the study were drawn across the selected areas.

\section{Instruments}

Two instruments were used to collect data; Beck Anxiety Inventory (BAI) developed by Beck et al. (1998) and Sexual Violence and Physical Abuse (SVPA) Scale developed by Lesserman et al. (1995). The BAI is a 21 items questionnaire that measures how people have been bothered by symptoms of anxiety for the past month including the current. The Beck Anxiety Inventory was developed by Beck, A.T., Epstein, N., Brown, G., Steer, R.A. (1988). The scale has a validity of .51 and a reliability of 0.75 .

Sexual Violence and Physical Abuse (SVPA) Scale is an 18 items questionnaire, that measures statements regarding sexual violence. The respondents indicated the extent to which they disagree or agree with the statements regarding sexual violence by ticking the appropriate number which represented their views in the corresponding response. It was pilot tested and had a reliability of .88 .

The demographic section was designed to collect demographic information such as gender, ethnic group, educational level, occupation, age and age at marriage of the respondents to give a meaningful interpretation of the results.

\section{Procedure}

Regarding the data collection procedures, consent was sought from each of the couples sampled for the study; questionnaires were administered on an individual basis in offices, homes, and houses. Each participant received a questionnaire with an informed consent letter and instructions for the survey. Confidentiality was strictly maintained and the data collected were only used for the study. The responses from the participants on the field were encouraging given that out of the 255 questionnaires that were distributed, 251 were retrieved and only 4 were missing. Two research assistants helped to distribute and retrieve the questionnaires from the participants in the selected areas covered for the study. 30 - 50 minutes were allowed for each participant. However, some questionnaires were not completed instantly, but the researchers were given a day to 2 days interval to retrieve the questionnaires. Clarifications to some statements were given to some participants before filling in the questionnaires and others were rigid and did not participate in the study. The entire fieldwork took two weeks for both administration and retrieval of the questionnaires.

\section{Data Analysis}

Data for this study were analyzed using descriptive and inferential statistics. Frequencies were used to present the demographics while Multiple Regression was used to test the hypotheses. All statistical data analysis was done using the statistical package for social sciences (SPSS) version 20.

\section{Results}

Hypothesis 1: There will be a significant influence of Gender, Age and Occupation on perceived anxiety among married couples in Makurdi metropolis; it was tested using regression analysis and the result is presented in the table below. 
IRA-International Journal of Management \& Social Sciences

Summary table of multiple regressions showing the influence of gender, age and occupation on perceived

\begin{tabular}{|c|c|c|c|c|c|c|c|}
\hline Variable & $\mathbf{R}$ & $\mathbf{R}^{2}$ & $\mathbf{F}$ & $\bar{\beta}$ & $\mathbf{t}$ & $\mathbf{P}$ & Remark \\
\hline Constant & .335 & .112 & 10.292 & & 16.268 & .000 & \\
\hline Gender & & & & .220 & 3.607 & .000 & $\mathrm{~S}$ \\
\hline Age & & & & -.152 & -2.501 & .013 & NS \\
\hline Occupation & & & & .237 & 3.879 & .000 & $\mathrm{~S}$ \\
\hline
\end{tabular}

The table above reveals that gender $(\beta=.220 ; \mathrm{P}<.05)$ and occupation $(\beta=.237 ; \mathrm{P}<.05)$ significantly influenced perceived anxiety while age $(\beta=-.152 ; \mathrm{P}<.05)$ negatively but significantly influenced perceived anxiety among married couples in Makurdi metropolis. Hence, the hypothesis is accepted $\mathrm{R}=.335, \mathrm{R}^{2}=.112$; $(3.244)=10.292$, $\mathrm{P}<.05$.

Hypothesis 2: There will be a significant influence of sexual violence on perceived anxiety among married couples in Makurdi metropolis; it was tested using regression analysis and the result is presented below.

\section{Summary table of simple linear regression analysis showing the influence of sexual violence on perceived}

\begin{tabular}{|c|c|c|c|c|c|c|c|}
\hline Variable & $\mathbf{R}$ & $\mathbf{R}^{2}$ & $\mathbf{F}$ & $\beta$ & $\mathbf{t}$ & $\mathbf{P}$ & Remark \\
\hline Constant & 415 & .172 & 50.896 & & 10.469 & .000 & \\
\hline Sexual Violence & & & & .415 & 7.134 & .000 & $\mathrm{~S}$ \\
\hline
\end{tabular}

The result above shows that sexual violence significantly influence perceived anxiety $R=.415, \mathrm{R} .172, \beta=.415, \mathrm{~F}$ $(1,245)=50.896 ; \mathrm{P}<.05$. This shows that sexual violence influences perceived anxiety among married couples in Makurdi Metropolis. The hypothesis is therefore accepted.

Hypothesis 3: There will be a significant joint influence of gender, age, occupation and sexual violence on perceived anxiety among married couples in Makurdi Metropolis; this was tested using regression analysis and the result is presented below.

Summary table of multiple regression analysis shown the joint influence of gender, age, occupation and sexual violence on perceived anxiety

\begin{tabular}{llllllll}
\hline Variable & $\mathbf{R}$ & $\mathbf{R}^{2}$ & $\mathbf{F}$ & $\boldsymbol{\beta}$ & $\mathbf{t}$ & $\mathbf{P}$ & Remark \\
\hline Constant & .471 & .222 & 17.219 & & 8.020 & .000 & \\
Gender & & & & .128 & 2.151 & .032 & $\mathrm{~S}$ \\
Age & & & & -.100 & -1.742 & .083 & NS \\
Occupation & & & & .186 & 3.211 & .002 & $\mathrm{~S}$ \\
Sexual violence & & & & .351 & 5.863 & .000 & $\mathrm{~S}$ \\
\hline
\end{tabular}

The result of the regression analysis above shows the significant joint influence of gender, age, occupation and sexual violence on Perceived anxiety $\mathrm{R}=.471, \mathrm{R}^{2}=.222 ; \mathrm{F}(4,242)=17.219 ; \mathrm{P}<.05$ the hypothesis is therefore accepted.

\section{Discussion}

Based on the hypotheses tested; hypothesis one which states that there will be a significant influence of gender, age and occupation on perceived anxiety among married couples in Makurdi metropolis was statistically significant. It means gender, age, and occupation of married couples will significantly influence Perceived anxiety. This is supported by findings of Yip, Rowlinson, \& Siu, (2008) who found that the experience of anxiety is gendered; and that males and females with different age brackets usually express anxiety, fear, and depression over time. McDaid and Park (2011), also agree that most depression, anxiety, and fear experienced by individuals are greatly related to their occupation. According to this study, age is found negatively but significantly influencing perceived anxiety. This is contrary to the finding of Lee (1977), who discovers that age influences greater depression, anxiety, and stress among married couples. 
Hypothesis two which states that there will be a significant influence of sexual violence on perceived anxiety among married couples in Makurdi metropolis was statistically accepted. This shows that sexual violence has a significant influence on perceived anxiety among married couples. This is in agreement with Petrak (2002), who found that anxiety and intense fear are primary responses following the act of sexual violence.

Hypothesis three which states that there will be a significant joint influence of gender, age, occupation and sexual violence on perceived anxiety among married couples in Makurdi metropolis was statistically supported. This means that gender, age, occupation, and sexual violence have a significant influence on perceived anxiety among married couples. This is consistent with Tjaden and Thoennes, (2000) who reviewed that in many settings and occupations at some time, 1 in six women have experienced an attempted rape, more than half occurred before the woman was 18 and during their lives, 1 in 33 men have experienced an attempted or complete rape as a form of sexual violence all reporting cases of one form of anxiety disorder or the other.

\section{Implications}

The implications of the findings are that gender, age and occupation influence perceived anxiety among couples. Also, male and female couples experience perceived anxiety. The age of the couples has no influence on perceived anxiety but the occupation of the couples plays a crucial role in the experience of perceived anxiety. The study indicates that married couples who engage in sexual violence will experience perceived anxiety and are likely to experience gynecological and other psychological problems. The findings indicate that gender, age, occupation, and sexual violence can at the same time influence perceived anxiety among married couples.

\section{Recommendations}

From the findings of the study, the following recommendations were made which are;

1. There is a need for psychologists especially clinical and counseling psychologists, and other related professionals to engage couples in both pre-marital and marital counseling programs and using interventions where necessary that will equip them for the challenges of marriage.

2. The government and policymakers on their part need to turn family-friendly policies to reduce the negative effects of sexual violence among married couples. These may include educating couples on human rights issues and provision of bye-laws and involving the judiciary to help checkmate and handle persons who are convicted of such acts.

3. Eliminating sexual violence against women in Africa, and Nigeria to be more specific requires a more comprehensive approach by professionals in the field, which can be developed to meet these needs of women- to be protected.

\section{References}

[1] Abekhale, S. O. (2010). Psychosocial effects of divorce on family off-springs in Gboko Local Government Area of Benue State. Counselling intervention strategies. Journal of Research in National Development 8 (1).

[2] Adeleke, N.A., Olowookere, A.S., Hassan, M.B., Komolafe, J.A \& Asekun-Olarimoye, E.O. (2012). Sexual assault against women at Osogbo, South-Western Nigeria. Nigerian Journal of Clinical Practice, 15 (2), 190-193.

[3] Akinlusi, F.M., Rabiu, A.K., Olawepo., Adewunmi, A.A., Othun, A.T. \& Akinola, O.I. (2014). Sexual assault in Lagos, Nigeria: a five year retrospective review. BMC Women's Health 14 (115)

[4] Australian Bureau of Statistics, (2005). Personal Safety Survey, Catalogue No4906.0

[5] Beck A.T, Epstein N, Brown G, Steer R.A, (1988). An inventory for measuring clinical anxiety psychometric properties. Journal of Consulting and Clinical Psychology, 56:893-897.

[6] Centers for Disease Control, (2005). The Emergency Response Safety and Health Data Base: Systematic Agent: BENZENE-NIOSE, www.cdc.gov. Retrieved 2016-01-27.

[7] Clark, H. \& Quadara, A. (2010). Insights into sexual perpetration: Giving voice to victim/survivors' knowledge (Research Report ND.B). Melbourns: AIFS.

[8] Eze, U.O. (2013). Prevention of sexual assault in Nigeria. Annals of Ibadan Postgraduate Medicine, 11 (2), 65-70

[9] Finkelhor, D., Hotaling, G., Lewis I.A., \& Smith, C. (1090). Sexual abuse in a national survey of Adult Men and Women: Prevalence, Characteristics, and Risk Factors of Child Abuse and Neglect 14, 19-26

[10] Hill, C \& Silva, E. (2005). Drawing the line sexual harassment on Campus $1^{\text {st }}$ Ed. USA American Association of University Women Educational Foundation.

[11] Lerner, J.S., Keltner, D. (2002). Beyond valance: Towards a model of emotion-specific influences on judgment and choice. Cognition and Emotion 14, 473-493. 
[12] Lee, S. (1977). Twelve - Month prevalence, correlates, and treatment preference of adults with DSM - major depressive episode in Hong Kong. Journal of Affective Disorders 98 (1 - 2): 129-36.

[13] Lesserman, J., Drossman, D.A Zhiming, R. (1995). The reliability and validity of a sexual and physical abuse history questionnaire in female patients with gastrointestinal disorders. Behaviour medicine, 21, $141-150$

[14] Lewis, S.H. \& Reed, E. (2003). Sexual Assault in Rural Communities http://www.wawnet.org/applied-researchpapers/print-document php?doc_id=419

[15] Miller-Keane, (2003). Anxiety-definition of anxiety in the medical dictionary. Retrieved from http://medical-dictionary The free dictionary.com/anxiety

[16] Mathurs, S, \& Khan, W. (2011). "Impact of hypnotherapy on examination anxiety and scholastic performance among school children”. Delhi Psychiatry Journal 14(2); 337-324

[17] Ma, D. (2017). Anxiety Symptoms and Immuno-endocrine Systems from Childhood to Adolescence: Understanding Reciprocal Change over Time (Doctoral dissertation, Concordia University)

[18] McDaid, D. \& Part, A.L (2011). "Investing in mental health and well-being: finding from the data Prev project". Health Promotion International 26 suppl 1: 108-139.

[19] Mgolozeli, S. E., \& Duma, S. E. (2019). “As I Was Walking Down the Street, Four Strange Guys Came and Took Me Under the Bridge, Where They All Raped Me": An Interpretative Phenomenological Analysis of the Types of Rape Experienced by Men in South Africa. American journal of men's health, 13(6), 1557988319882589.

[20] Owen, I. R. (1994). Introducing an existential-phenomenological approach Part 2-theory for practice. Counselling Psychology Quarterly, 7(4), 347-358

[21] Ohman, (1993). "Fear and Anxiety: Evolutionary, Cognitive, and Clinical perspectives". In Lewis, Michael; HavilandJones, Jeannette M. Handbook of emotions, New York. The Guildford press Pp.573-93. ISBN 978-1-57230-529-8

[22] Olive, V.C. (2012). Sexual assault against women of colour. Journal of Student Research, 1, 1-9

[23] Ormel, J., Jeronimus, B.F., Kotov, M., Riese, H., Bos, E.H., \& Hankin, B. (2013). "neuroticism and common mental disorders: meaning and utility of a complex relationship" Clinical Psychology Review, 33(5): 686-697

[24] Ogbuji, C. Q. (2004). Violence against women: impact on their reproductive health. Tropical Journal of Obstetrics and Gynaecology, 21(1), 61-64.

[25] Patrak, J. (2002). The psychological impact of sexual assault. In J. Petrak\& B. Hedge (Eds.) Thetrauma of sexual assault: Treatment, prevention and practice. West Sussex: John Wily \& sons.

[26] Seligman, M.E.P; Walker, E.F., Rosenhan, D.L. (2002). Abnormal Psychology (4 ${ }^{\text {th }}$ Ed.). New York: W.W Norton \& Company

[27] Tjaden, P., Thoennes, N. (2000). Full report of the prevalence, incidence and consequences of violence against women: Findings from the National violence against women survey, Washington (DC): National Institute of Justice; Report NCJ 183781

[28] Teigen, Karl Halvor (1994). "Yerkes-Dodson: A law for all seasons". Theory Psychology 4 (4): 525-47

[29] Shija, M.T. (2004). Domestic violence and its impact on women's rights. Paper on domestic violence and draft bill, Benue State, Nigeria.

[30] Thompson, R. A. (2011). Emotion and emotion regulation: Two sides of the developing coin. Emotion Review, 3(1), 53-61.

[31] Odimegwu, C., \& Okemgbo, C. N. (2008). Men's Perceptions of Masculinities and Sexual Health Risks in Igboland, Nigeria. International Journal of Men's Health, 7(1).

[32] West, C.M \& Rose, S. (2000). Dating aggression among low income African American Youth: An examination of gender difference and antagonistic beliefs. Violence against women 6, 470-494.

[33] Yip, B., Rowlinson, S., \& Siu, O. L. (2008). Coping strategies as moderators in the relationship between role overload and burnout. Construction Management and Economics, 26(8), 871-882.

[34] WHO (1999). Sexual violence prevalence, dynamics and consequences. 